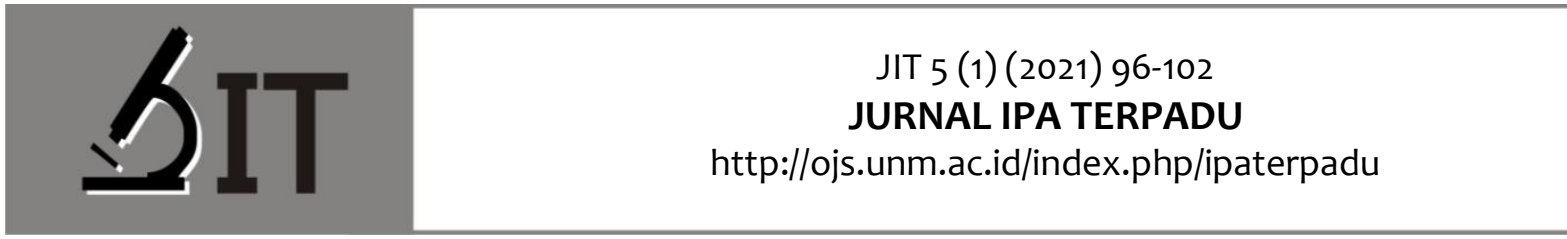

p-ISSN : 2597-8977

e-ISSN : $2597-8985$

Jusniar *)

Universitas Negeri Makassar

Syamsidah

Universitas Negeri Makassar

\section{HUBUNGAN KONSEP DIRI DENGAN MISKONSEPSI SISWA PADA KONSEP KESETIMBAGAN KIMIA}

Abstrak: Penelitian survey ini bertujuan mendeskripsikan hubungan antara konsep diri siswa dengan miskonsepsinya pada konsep Kesetimbangan Kimia (KK). Subjek penelitian sebanyak 235 siswa dari tiga SMA di kabupaten Gowa (80 siswa SMAN 1 Gowa; 83 Siswa SMAN 2 Gowa; dan 72 siswa SMAN 3). Penelitian ini dilakukan pada semester Ganjil 2018/2019. Instrumen Tree-tier Diagnostik pada konsep KK sebanyak 30 item dan angket konsep diri siswa pada konsep KK 20 item. Hasil penelitian menunjukkan konsep diri berkorelasi negatif dengan jumlah miskonsepsi siswa pada konsep KK (masing-masing -0,384, -0,254, dan -0,327). Hal ini menunjukkan bahwa semakin baik konsep diri siswa pada konsep-konsep Kesetimbangan Kimia, maka akan semakin kecil jumlah miskonsepsi yang dialaminya.

Kata Kunci: Konsep diri, miskonsepsi, Kesetimbangan Kimia

Abstract: This survey study aims to describe the relationship between students' self-concepts and their misconceptions about the concept of Chemical Equilibrium (CE). The research subjects were 235 students from three high schools in Gowa district (80 students of SMAN 1 Gowa; 83 students of SMAN 2 Gowa; and 72 students of SMAN 3). This research was conducted in the 2018/2019 Odd semester. The Diagnostic Tree-tier instrument on the CE concept is 30 items and the students' self-concept questionnaire on the CE concept is 20 items. The results showed that selfconcept was negatively correlated with the number of students' misconceptions about the CE concept $(-0.384,-0.254$, and -0.327) respectively. This shows that the better the students' self-concepts on the concepts of Chemical Equilibrium, the smaller the number of misconceptions they experience.

Key word: Self-concept, misconceptions, Chemical Equilibrium

*) Correspondence Author: jusniar@unm.ac.id 


\section{PENDAHULUAN}

Topik Kesetimbangan Kimia penting dipahami dengan utuh karena merupakan dasar untuk memahami materi yang berhubungan, seperti kesetimbangan asam-basa, hidrolisis, dan kelarutan (Voska \& Heikkinen, 2000). Kesetimbangan kimia merupakan salah satu topik dengan konsepkonsep yang bersifat kompleks dan sulit untuk dipelajari (Maia \& Justi, 2009; Quiles, 2004; Koutshana, et al., 2002; Tyson, et al., 1999). Hal ini diduga berhubungan dengan karakteristik topik ini yang mencakup konsep terdefinisi, konsep abstrak, hitungan matematis, dan grafik. Karakteristik tersebut membuat siswa cenderung mengalami kesulitan memahami konsep. Kesulitan ini pada akhirnya menyebabkan kesalahan memahami konsep. Kesalahan memahami konsep yang terjadi secara konsisten berpotensi adanya miskonsepsi. Miskonsepsi adalah pemahaman konsep yang tidak sesuai dengan pemahaman para ahli (Barke, et al., 2009; Herron, 1996; dan Nakhleh, 1992). Kesalahan konsep disebut juga dengan konsep alternatif (Horton, 2007).

Beberapa miskonsepsi yang terjadi pada topik kesetimbangan kimia diantaranya sebagai berikut. Laju reaksi maju lebih cepat pada keadaan setimbang (Niaz, 1998 dan Hackling \& Garnett, 1985). Keadaan setimbang tercapai ketika konsentrasi reaktan dan produk sama (Yakmaci-Guzel, 2013; Barke, et al., 2009; Özmen, 2008; Hackling \& Garnett, 1985). Kenaikan temperatur menyebabkan laju reaksi maju menurun dan laju reaksi balik meningkat (Barke, et al., 2009; Bilgin \& Uzuntiryaki, 2003; dan Hackling \& Garnett, 1985). Kesetimbangan adalah proses yang statis (Yakmaci-Gusel, 2013; Barke, et al., 2009). Kesetimbangan dinamis adalah kondisi dimana konsentrasi berubah-ubah (Jusniar, et al, 2020) Pada reaksi eksotermik, kenaikan temperatur akan menurunkan laju reaksi maju (Sozbilir, et a, 2010; Banerjee, 1991). Harga K yang besar menyebabkan reaksi maju berlangsung lebih cepat (Bilgin \& Uzuntiryaki, 2003; Banerjee, 1991; Hackling \& Garnett, 1985). Penambahan reaktan (fase padat) pada sistem kesetimbangan heterogen menyebabkan reaksi bergeser ke arah produk (Piquitte \& Heikkinen, 2005). Penambahan reaktan pada sistem kesetimbangan gas akan menggeser kesetimbangan ke arah produk (Karpudewan, et al., 2015). Katalis menyebabkan peningkatan konsentrasi produk (Bilgin \& Uzuntiryaki, 2003; Voska \& Heikkinen, 2000; Gorodetsky \& Gussarsky, 1986; dan Hackling \& Garnett, 1985). Jadi, miskonsepsi terjadi pada hampir seluruh konsep kesetimbangan kimia.

Miskonsepsi dapat disebabkan oleh beberapa faktor diantaranya adalah pengetahuan awal (Taber, 2002), komunikasi yang tidak efektif (Dhindsa \& Treagust, 2014; Johnstone, 2010), Miskonsepsi pada konsep prasyaratnya (Jusniar et al, 2020); ketidakcukupan informasi yang diberikan oleh guru dan keterbatasan isi buku teks (Erman, 2017; Devetak, et al., 2010; Garnet, et al., 1995), sifat abstrak dan simbolik konsep kimia (Yakmaci-Guzel, 2013), dan prakonsepsi siswa (Barke, et al., 2009; Horton, 2007). Akibatnya siswa membangun pengetahuannya berdasarkan pada miskonsepsinya (Taber, 2011).

Selain faktor-faktor di atas Pintrich (1996) mengemukakan bahwa pemahaman konsep juga dipengaruhi oleh aspek afektif seperti minat, motivasi, self efficacy, self esteem dan self konsep. Secara spesifik Baur (2005) berpendapat bahwa pemahaman konsep kimia dipengaruhi oleh konsep dirinya. Indikator konsep diri terdiri dari lima yaitu konsep diri tentang matematika, kimia, akademik, kreatifitas dan kesenangan akademik serta konsep diri problem solving (Nielsen \& Yezierski, 2015). Lewis, et al. (2009) melaporkan bahwa konsep diri (Self concept) merupakan salah satu prediktor kuat yang berpengaruh terhadap pengetahuan konseptual dan psikomotorik anak serta keberhasilan dalam pemahaman kimia umum. Nielsen \& Yezierski (2015) melaporkan bahwa self konsep siswa / mahasiswa berkorelasi dengan hasil tes Mozart (misconception orientation standart based assessment resource for teacher) dengan nilai koefisien korelasi 0.35. Menurut Bong \& Skaalvik (2003) konsep diri telah diidentifikasi sebagai komponen yang berorientasi lampau, berkontribusi dalam model harapan, motivasi dan perubahan konseptual anak. Berdasarkan hal tersebut diduga bahwa konsep diri berkorelasi positif maupun negatif terhadap pemahaman konsep dan miskonsepsi yang dimiliki mahasiswa. Sebagaimana karakteristik 
miskonsepsi bahwa konsep yang dipahami salah sulit untuk diubah karena menurut mereka benar dan masuk akal (Papaphotis \&Tsaparlis, 2008).

Berdasarkan fenomena di atas di duga bahwa konsep diri siswa berhubungan dengan miskonsepsi kesetimbangan kimia. Boleh jadi antara siswa yang paham konsep dan yang salah konsep keduanya memiliki self konsep yang tinggi dan harus dikonfirmasi dengan hasil tes miskonsepsi pada konsep kesetimbangan kimia. Pertanyaan penelitian yang diajukan adalah: Apakah ada korelasi antara konsep diri siswa dengan miskonsepsi siswa pada konsep Kesetimbangan Kimia?

\section{METODE}

\section{Jenis dan Sampel Penelitian}

Penelitian ini merupakan penelitian survey yang bersifat korelasional. Subjek penelitian sebanyak 235 siswa dari tiga SMA di kabupaten Gowa (80 siswa SMAN 1 Gowa; 83 Siswa SMAN 2 Gowa; dan 72 siswa SMAN 3). Teknik sampling diambil secara acak yang bersifat insedentil. Pemberian tes dilakukan kepada siswa berturut-turut yakni tes miskonsepsi (waktu 60 menit) kemudian angket konsep diri (durasi 15 menit).

\section{Instrumen Penelitian}

Penelitian ini dilakukan pada semester Ganjil 2018/2019. Pengumpulan data dilakukan dengan menggunakan instrumen Tree-tier Miskonsepsi pada konsep KK (TMKK) sebanyak 30 item yang telah dikembangkan oleh Jusniar, et al (2020) dan angket konsep diri siswa pada konsep KK 20 item diadaptasi dari Bauer (2005).

Tes Miskonsepsi Kesetimbangan Kimia (TMKK) ini berbentuk three tier sebanyak 30 item terdiri 6 item konsep keadaan setimbang dan kesetimbangan dinamik, 4 item konsep kesetimbangan, 5 item konsep $K_{c}$ dan $K_{p}, 2$ item konsep tetapan $K$ pada kesetimbangan heterogen, 11 item konsep faktor-faktor yang mempengaruhi pergeseran kesetimbangan dan 2 item konsep aplikasi Kesetimbangan Kimia di industri. Tier pertama berisi soal yang terdiri dari empat pilihan jawaban, tier kedua berisi alasan yang terdiri dari empat pilihan alasan dan tier ketiga berisi keyakinan dari jawaban dan alasan dengan tiga pilihan yaitu 1) menerka, 2) tidak yakin, dan 3) yakin. Penentuan siswa yang mengalami miskonsepsi mengadaptasi kriteria yang ditetapkan oleh Arslan, et al. (2012) seperti pada Tabel 1. Sebelum digunakan TMKK telah divalidasi isi dan empirik.

Tabel 1. Kriteria Pengelompokan Konsepsi Siswa Berdasarkan Three Tier Test

\begin{tabular}{|c|c|c|c|}
\hline First tier & $\begin{array}{l}\text { Second } \\
\text { tier }\end{array}$ & Third tier & Kategori \\
\hline Benar & Benar & Yakin & Paham konsep \\
\hline Benar & Benar & Tidak yakin/menerka & $\begin{array}{l}\text { Paham konsep (tidak percaya } \\
\text { diri) }\end{array}$ \\
\hline Benar & Salah & Tidak yakin/menerka & Pemahaman kurang \\
\hline Salah & Benar & Tidak yakin/menerka & Pemahaman kurang \\
\hline Salah & Salah & Tidak yakin/menerka & Pemahaman kurang \\
\hline Benar & Salah & Yakin & Miskonsepsi \\
\hline Salah & Benar & Yakin & Miskonsepsi \\
\hline Salah & Salah & Yakin & Miskonsepsi \\
\hline
\end{tabular}

Angket konsep diri siswa pada konsep kesetimbangan kimia terdiri dari 20 item yang memuat tiga aspek yaitu: confidence of understanding; class contribution and achievement 
appraisal. Angket ini diadaptasi dari Bauer (2005), yang mana memuat pernyataan-pernyataan tentang konsep kimia secara umum di spesifikkan dengan konsep keseteimbangan kimia.

Wawancara semi struktur dilakukan dengan menggunakan pedoman hasil analisis angket konsep diri dan TMKK. Dilakukan terhadap siswa yang memiliki skor angket konsep diri tinggi (memiliki keyakinan memahami konsep), namun jumlah miskonsepsinya tergolong tinggi.

\section{Analisis Data}

Data dianalisis dengan teknik analisis deskriptif dan korelasi dengan menggunakan berbagai sumber data penelitian. Korelasi Pearson digunakan untuk menentukan hubungan antara skor konsep diri siswa dengan jumlah miskonsepsinya pada konsep KK. Analisis ini dilakukan dengan menggunakan SPSS for windows 21.0. Uji ini digunakan karena semua kelompok skor konsep diri dan jumlah miskonsepsi berdistribusi normal. Deskripsi konsep diri dan jumlah miskonsepsi untuk kategori tinggi adalah siswa yang memperoleh skor atau jumlah miskonsepsi di atas rata-rata. Kategori konsep diri dan jumlah miskonsepsi rendah jika skor di bawah rata-rata, hal ini merujuk pendapat Brigdes and Harnish (2015).

\section{HASIL DAN PEMBAHASAN}

\section{Hasil Penelitian}

Deskripsi data hasil penelitian tentang konsep diri siswa, jumlah miskonsepsi yang dialami pada konsep Kesetimbangan Kimia dapat dilihat pada Tabel 2.

Tabel 2. Statistika Deskriptif Konsep Diri, Jumlah Miskonsepsi Siswa, dan Hasil Korelasinya

\begin{tabular}{|c|c|c|c|c|c|c|}
\hline \multirow[t]{2}{*}{ Data } & \multicolumn{2}{|c|}{ SMAN 1 GOWA } & \multicolumn{2}{|c|}{ SMAN 2 GOWA } & \multicolumn{2}{|c|}{ SMAN 3 GOWA } \\
\hline & Skor KD & JM & Skor KD & $J M$ & Skor KD & JM \\
\hline Jumlah sampel & 80 & 80 & 83 & 83 & 72 & 72 \\
\hline Mean & 47,81 & 7,99 & 46,77 & 6,76 & 46,78 & 7,92 \\
\hline SD & 8,70 & 4,05 & 10,39 & 3,97 & 11,11 & 3,61 \\
\hline Skor Ideal & 80 & 30 & 80 & 30 & 80 & 30 \\
\hline Jumlah & & $43(53,8)$ & $35(42,2)$ & $37(44,6)$ & $33(45,8)$ & 27 \\
\hline $\begin{array}{l}\text { Kategori tinggi } \\
\text { (\%) }\end{array}$ & $34(42,5 \%)$ & & & & & $(37,5)$ \\
\hline $\begin{array}{l}\text { Jumlah } \\
\text { Kategori } \\
\text { rendah (\%) }\end{array}$ & $46(57,5 \%)$ & $37(46,2)$ & $48(57,8)$ & $46(55,4)$ & $39(54,2)$ & $\begin{array}{l}45 \\
(62,5)\end{array}$ \\
\hline $\begin{array}{l}\text { Harga Korelasi } \\
\text { Pearson KD-JM }\end{array}$ & & & & & & \\
\hline
\end{tabular}

\section{Pembahasan}

Berdasarkan data pada Tabel 2 terlihat bahwa dari tiga sekolah di Kabupaten Gowa menunjukkan bahwa terdapat korelasi negatif yang signifikan antara jumlah miskonsepsi dengan konsep diri siswa pada konsep Kesetimbangan Kimia. Penguian korelasi Pearson dilakukan pada tiga sekolah tersebut setelah Uji persyaratan normalitas terpenuhi. Korelasi negatif diinterpretasikan bahwa siswa dengan konsep diri tinggi mengalami sedikit miskonsepsi (jumlah miskonsepsinya kecil). Ini tentunya sangat diharapkan karena konsep diri tinggi dan tepat menunjukkan tidak terjadinya miskonsepsi pada siswa. Sebaliknya konsep diri siswa yang tinggi boleh jadi terjadi kesalahan memahami konsep. Ini diindikasikan dengan korelasi yang positif antara konsep diri dengan jumlah miskonsepsi siswa .

Hal ini didukung oleh gambaran persentase konsep diri kategori tinggi yang berturut turut besarnya 42,5, 42,2, dan 45,8\%. Sementara jumlah miskonsepsi kategori tinggi juga beturut-turut 
$53,8,44,6$, dan $37,5 \%$. Fenomena ini menunjukkan bahwa konsep diri siswa yang tinggi, belum tentu memiliki pemahaman yang baik.

Dengan demikian konsep diri siswa pada konsep KK boleh jadi berkorelasi positif maupun negatif terhadap pemahaman konsep dan miskonsepsi yang dimiliki siswa. Sebagaimana karakteristik miskonsepsi bahwa konsep yang dipahami salah, sulit untuk diubah karena menurut mereka benar dan masuk akal (Papaphotis \&Tsaparlis, 2008).

Beberapa miskonsepsi yang ditemukan dimana siswa yang memiliki konsep diri dengan skor yang tinggi mengalami miskonsepsi diantaranya: Miskonsepsi (1) Pada kondisi setimbang laju peningkatan jumlah reaktan lebih cepat dari pada laju penurunan jumlah produk. Pernyataan miskonsepsi (1) didukung dengan hasil wawancara terhadap siswa yang mengalami miskonsepsi ini dengan konsep diri yang tinggi artinya merasa benar pemahamannya.

$P$ : "Pada item (3) dari TMKK ; bagaimana laju reaksi maju dibandingkan

dengan laju reaksi balik dalam keadaan setimbang?"

S: "Reaksi akan berlangsung terus dengan laju reaksi maju lebih besar

daripada sebaliknya reaksi.

P: Mengapa Anda berpendapat begitu?

$S$ : Kondisi kesetimbangan bersifat dinamis yang artinya berubah-ubah

Nampaknya siswa yang miskonsepsi tersebut berpendapat demikian, karena mengalami kesalahan memahami bahwa "pada kondisi kesetimbangan" reaksi maju dan reaksi balik bervariasi karena jumlah reaktan dan produk juga bervariasi. Miskonsepsi ini telah dilaporkan oleh Jusniar, et al (2020). Dengan demikian, laju reaksi juga bervariasi dan menurutnya lebih cepat ke arah pembentukan produk.

Miskonsepsi di atas perlu untuk diluruskan. Konsep yang benar adalah pada kondisi setimbang laju reaksi ke arah produk sama dengan laju reaksi balik. Makna kesetimbangan dinamis adalah pada kondisi setimbang reaksi berlangsung terus meskipun secara makroskopik sudah tidak terjadi lagi perubahan, namun secara mikroskopik reaksi dalam dua arah tetap berlangsung dengan laju yang sama (Burdge \& Overby, 2017).

Miskonsepsi (2) pada kesetimbangan $\mathrm{H}_{2}(\mathrm{~g})+\mathrm{Br}_{2}(\mathrm{~g}) \rightleftharpoons 2 \mathrm{HBr}(\mathrm{g})$, peningkatan volume sistem akan menggeser kesetimbangan ke arah kiri. Hasil wawancara kepada siswa yang miskonsepsi dengan skor konsep diri tinggi diperoleh bahwa:

Miskonsepsi ini disebabkan karena siswa memahami subskrip $\mathrm{H}$ dan $\mathrm{Br}$ sebagai jumlah mol. Siswa ini memahami bahwa jumlah mol pada ruas kiri adalah empat mol, dan pada kanan, ada dua tahi lalat. Siswa-siswa ini tidak konsisten dalam menggunakan koefisien dengan indeks atau subscript untuk mengekspresikan

jumlah mol zat dalam persamaan reaksi.

Konsep yang benar adalah jumlah mol pada kedua sisi sama, sehingga perubahan tekanan/volume gas tidak akan menggeser posisi kesetimbangan. Penurunan volume gas menyebabkan pergeseran kesetimbangan ke arah jumlah mol gas yang sedikit (Burge \& Overby, 2017). Namun untuk reaksi pada fasa gas antara hidrogen dengan bromin menghasilkan hidrogen bromida, perubahan volume sistem tidak menggeser sistem kesetimbangan karena jumlah mol sisi kiri dan kanan sama.

Berdasarkan temuan-temuan yang dipaparkan nampak bahwa tidak semua siswa dengan konsep diri tinggi pemahamannya akan tepat atau tidak mengalami miskonsepsi. Karakteristik konsep diri adalah multidimensi (7kognitif dan afektif) dan berorientasi pada apa yang telah dimiliki oleh siswa dan bersifat stabil (Bong \& Skaalvik, 2003). Beberapa karakteristik konsep diri relatif sesuai dengan sifat miskonsepsi seperti relatif stabil, dimensinya kognitif, dan berorientasi lampau atau telah dimiliki siswa.

Beberapa keterbatasan penelitian survey ini diantaranya adalah tidak adanya perlakuan yang diterapkan dalam penelitian ini. Misalnya perlakuan dalam rangka mengeliminasi miskonsepsi yang 
terjadi atau meningkatkan konsep diri siswa. Sehingga menjadi rekomendasi untuk disempurnakan oleh peneliti selanjutnya.

\section{KESIMPULAN}

Ada korelasi negatif yang signifikan antara konsep diri siswa dengan miskonsepsinya pada pemahaman konsep Kesetimbangan Kimia pada tiga SMA di Kabupaten Gowa Sulawesi Selatan. Interpretasi dari harga $r$ berkorelasi negatif adalah siswa dengan tingkat konsep diri tinggi, kecil kemungkinannya mengalami miskonsepsi. Peneliti lebih lanjut dapat mengeksplorasi hubungan konsep diri dengan variable-variable lain. Atau dapat menggunakan pendekatan penelitian kualitatif lainnya.

\section{DAFTAR PUSTAKA}

Arslan, H.O., Cygdemoglu, C., \& Moseley, C. (2012). A-Three-Tier Diagnostic Test to AssessPre-

Service Teachers' Misconceptions about Global Warming, Greenhouse Effect, Ozone Layer Depletion, and Acid Rain. International Journal of Science Education, 34(11): 1667-1686.

Banerjee, A.C. (1991). Misconceptions of Students and Teachers in Chemical Equilibrium. International journal of Science Education, 13(4): 487-494.

Barke, H.D; Hasari, A; Yitbarek D. (2009). Misconceptions in Chemistry. Book Chapter (145-170). Verlag Berlin Heidelberg: Springer.

Bauer, C.F. 2005. Beyond "Student attitude": Chemistry Self Concept Inventory for Assesment of the Affective Component of Student Learning. Journal Chemical Education, 82(12), 1864-1870.

Bong, M \& Skaalvik, E.M. 2003. Academic Self Concept and Self Efficacy: How Different are They Really? Educationan Physicology Review, 15(1), 1-40.

Bilgin, I, Uzunttiryaki, E, (2003). Students' Misconception on the Concept of Chemical Equilibrium.Education and Science, 28(127): 10-17.

Burdge, J., \& Overby, J. (2017). Chemistry atom (3rd ed.). McGraw Hill.

Gorodetsky, M. \& Gussrasky, E. (1986). Misconceptualization of the Chemical

Equilibrium Concept as Revealed by Different Evaluation Methods. Euoropa Journal Science Education. 8(4): 427-441.

Hackling, M. W \& Garnett, P. J. (1985). Misconceptions of Chemical Equilibrium. European Journal of Science Education, 7(2), 205-214. https://doi. org/10.1080/0140528850070211

Herron, J.D. (1996). The Chemsitry Classroom Formula for Successful Teaching. Whasington, DC: American Chemical Society.

Horton, C. (2007). Students Alternative Conception in Chemistry. California Journal of Science Education, 7(2): 18-38.

Jusniar, Effendy, Budiasih, E., \& Sutrisno. (2019). The Misconception of Stoichiometry and its Impact on the Chemical Equilibrium. Advance in Social Science, Education, and Humanities Research. 227, 138-141.

Jusniar, J., Effendy, E., Budiasih, E., \& Sutrisno, S. (2020). Developing a three-tier diagnostic instrument on chemical equilibrium (TT-DICE). Educacion Quimica, 31(3), 84-102. https://doi.org/10.22201/fq.18708404e.2020.3.72133

Karpudewan, M., Treagust, D. F., Mocerino, M., Won, M., Chandrasegaran, A.L. (2015). Investigating High School Students' Understanding of Chemical Equilibrium Concepts. International Journal of Enviromental \&Science Education, 10 (6): 845-863.

Koutshana, M \& Tsaparlis, G. (2002).Students' Errors in Solving Numerical-Equlibrium Problems. Chemistry Education: Research and Practice in Europe, 3(1): 5 -17. 
Nakhleh, M.B, (1992). "Why Some Student Don't Learn Chemistry (Chemical Misconception)". Journal of Chemical Education, 59(3): 191-194.

Nielsen, S.E \& Yezierski, E. 2015. Eksploring the Struktur and Function of the Chemistry Self Concept Inventory With High School Chemistry Scudent. Journal of Chem. Eduation, 1-8

Nieswandt, M. 2007. Student Affect and Conceptual Understanding in Learning Chemistry. Journal of Research in Science Teaching, 44(7), 908-937.

Özmen H. (2008). Determination of Students' Alternative Conceptions about Chemical equilibrium: a Review of research and the Case of Turkey. Journal Chemistry Education Research and Practise, 9, 225-233.

Piquitte, J. S. \& Heikkinen, H. W. (2005). Strategies Reported Used by Instructors to Address Student Alternate Conceptions in Chemical Equilibrium. Journal of Research in Science Teaching, 42 (10): 1112-1134.

Quilez, J; Solaz, J.J. (1995). Students' and Teachers' Misapplication of Le Chatelier's Principle: Implication for the Teaching of Chemical Equilibrium. Journal of Research in Science Teaching, 32(9), 939-957.

Sozbilir, M., Pinarbasi, T., Conpolat. (2010). Prospective Chemistry Teachers' Conceptions of Chemical. Eurasia Journal of Mathematic, Science, and Technology Education, 6(2): 111-120.

Tyson, L; Treagust, D.F; Bucat, R.B. (1999). The complexity and Leaching and Learning Chemical Equilibrium. Journal of Chemical Education, 79 (4), 554-558.

Voska, K.W \& Heikkinen, H.W. (2000). Identification and Analisys of Students Conception Used to Solve Chemical Equilibrium Problems. Journal of Research in Science Teaching. (32) (2): 160176.

Yakmaci-Guzel, B. 2013. Preservice Chemistry Teacher in Action: As Evaluation of Attempts for Changing High School Students' Chemistry Misconception into More Scientific Conception. Chemistry Education Research and Practice, 14, 95-104.

Received, 01 September 2021

Accepted, 30 September 2021

\section{Jusniar}

Dosen Program Studi Pendidikan Kimia FMIPA UNM, aktif melakukan penelitian pada bidang pendidikan kimia, dapat dihubungi melalui email: jusniar@unm.ac.id

\section{Syamsidah}

Dosen Program Studi Pendidikan Kesejahteraan Keluarga FT UNM, aktif melakukan penelitian pada bidang pendidikan kesejahteraan keluarga, dapat dihubungi melalui email: syamsidah@unm.ac.id 